\title{
Exploring intentions to teach mathematical problem solving: An application of the Theory of Planned Behaviour
}

\author{
P. Hamidu-Armah ${ }^{1}$ and D. Robson ${ }^{2}$
}

\begin{abstract}
This study examined the beliefs underlying teachers' decision-making regarding teaching Mathematical Problem Solving (MPS), from the perspective of the Theory of Planned Behaviour (TPB). 375 primary teachers drawn from 50 schools in a large, mainly urban local authority in Ghana, completed a questionnaire assessing the direct TPB measures of attitudinal beliefs (positive/negative consequences), normative beliefs (approving/disapproving significant others), control beliefs (easy/difficult circumstances) and intentions in relation to teaching MPS. In the follow up qualitative phase, six semi-structured teacher interviews were conducted to further explore the quantitative findings. The merged results revealed that teachers' intentions to teach MPS were influenced by their attitudinal beliefs towards teaching MPS (e.g. stimulate critical thinking, apply mathematics to everyday contexts), their perceptions and actions of important others (e.g. education authorities, pupils and parents), and some perceived control difficulties (e.g. lack of instructional resources and time availability). The results identified both attitudinal and control beliefs as the main determinants of teacher intentions to teach MPS. These findings highlight the key beliefs to target in developing the capacity of schools to support mathematics teachers' willingness to implement curriculum reform imperatives.
\end{abstract}

Keywords: mathematical problem solving; teacher beliefs and intentions; teacher cognition and practice; mathematics curriculum implementation

\section{Introduction}

Since the 1970s, there has been considerable global interest in shaping the focus of school mathematics away from more traditional approaches (Pampaka, 2014) towards what is now commonly called 'developing mathematical power', emphasising reasoning, investigation and problem solving, and communication of mathematics to others (National Research Council, 2001). Early developments in the UK and USA (Her Majesty's Inspectorate, 1985; NCTM, 1980) recommended problem solving, contextualised and based on practical experience, as the focus of school mathematics. Subsequently, numerous studies (e.g. OECD, 2013) have documented the importance of teaching mathematical problem solving (MPS), in stimulating increased conceptual understanding and in preparing pupils to apply their knowledge in innovative ways. Many mathematics educators have since argued that problem solving is a very important, if not the most important, goal of mathematics instruction at every level (Anderson, 2009).

Despite this global imperative, it was not until 2007 that the education authorities in Ghana launched a new national curriculum, highlighting the need to develop pupils' capacity to apply

\footnotetext{
${ }^{1}$ Prince Hamidu Armah is a lecturer at the Department of Mathematics Education, University of Education, Winneba. Ghana. Email: pharmah@uew.edu.gh. $\square$

${ }^{2}$ Dean Robson is a Senior Lecturer in Mathematics Education in the University of Aberdeen, United Kingdom

Open Access article distributed under the terms of the Creative Commons Attributions License [CC BY-NC-ND 4.0] http://creativecommons.org/licenses/by-nc-nd/4.0. DOI: https://dx.doi.org/10.4314/ajesms.v15i1.10
} 
their mathematical knowledge and skills to solve problems (MOESS, 2007). Inherent in the curriculum reform agenda was the expectation to teach mathematics, not as a fixed collection of facts and procedures, but as a dynamic body of knowledge continually enriched through exploration, analysis, generalisation, and conjecture (MOE, 2012).

However, a decade on, much empirical evidence in Ghana continues to raise concerns about how school teachers deliver mathematics, particularly problem solving and investigations. There remains an over-emphasis on expository teaching with limited opportunities for learners to engage in activities that will enable them to use concepts, solve non-routine problems and reason mathematically (Ampadu, 2012; MOE, 2014a). Even where problem solving is taught, "the solution of [word] problems has been reduced to a method, formula or recipe, rather than the making of a plan to solve a problem" (MOE, 2014b, p.34), resulting in poor student performance when required to apply their knowledge of numeric and algebraic concepts, express generalizations algebraically and innovatively model situations (Anamuah-Mensah, Mereku \& Asabere-Ameyaw 2004; MOESS, 2008). Ghana has consistently trailed behind its competitors in international comparisons (e.g. TIMSS) that emphasise solving non-routine problems and mathematical reasoning (Mullis et al., 2012).

The Ghanaian curriculum remains overloaded, with limited professional development opportunities for teachers in teaching and assessing MPS (Armah, 2017), although reform efforts have supported child-centred classroom practices. This can pose a multitude of instructional impediments to a teacher's transition to the reform expectations that reflects their new role as "people who engage the class in mathematical investigation, orchestrate classroom discourse, and create a learning environment that is mathematically empowering" (Herrera \& Owens, 2001, p. 90). Ernest (2004) argues that any change in instructional approach is not just a matter of curriculum reform, but fundamentally involves deeper changes to a teacher's beliefs system as this forms the cognitive foundation for instructional decisions and pedagogical change. Teacher beliefs do not only affect the way they teach, but also what and how their pupils learn, and attempts to stimulate mathematical problem solving instruction may yield better results when teacher beliefs are considered and challenged (Pampaka, 2014). The study reported here attempts to understand the interplay between teachers' beliefs and their reform implementation decisions, and to unpack how the knowledge of such interactions can successfully guide capacity building efforts for teachers to implement mathematics reforms.

\section{Understanding teacher beliefs and practice-theoretical considerations}

Norton et al. (2005) describe teaching as an occupation fundamentally guided by beliefs which, together with the associated thought processes, underpin their actions. Thus, examining the influences on, and relationship between, mathematics teachers' beliefs and teaching practice has gained considerable attention (e.g. Anderson, 2009; Ernest, 2004). Although some evidence appears to suggest a direct relationship between teacher beliefs and practice, in general, the link appears unclear. Some studies (e.g. OECD, 2009) have found direct relationship between teacher beliefs and practice. Others (e.g. Polly et al., 2013) have equally found inconsistency between teacher beliefs and practice, reinforcing the apparent lack of clarity on how teacher beliefs affect their classroom situational decisions and practice. In this study, we attempt to address this tension in the literature using an influential reasoned-action model, Ajzen's (1991) Theory of Planned Behaviour (TPB). The application of the TPB as a framework in this study should, however, be viewed as a mere representation, rather than a description, of reality. 
The TPB model suggests that the interaction between beliefs and practice can be explained better with the concept of behavioural intentions, highlighting intentions (rather than beliefs) as the immediate antecedent predictors of behaviours (Fishbien \& Ajzen, 2010). Intentions, understood as how hard people are willing to try or how much effort they are willing to exert to execute a behaviour, are hypothesised to be a linear function of attitudes, subjective norms, and perceived behaviour control (PBC) about the target behaviour.

Attitude towards behaviour is defined as a person's overall evaluation of performing the behaviour in question, which represents the person's favourable or unfavourable feelings. The current understanding is that attitudinal formation can emerge from instrumental and/or affective considerations. Instrumental attitudes relate to the cognitive consideration of the consequences (e.g. advantages or disadvantages) of performing the behaviour whilst affective attitudes concern the emotional experiences (e.g. like or dislike) emerging from performing the behaviour (Wilson et al., 2016).

Subjective norms reflect the perception that people whose opinion the person values (i.e. referents) think they should perform the behaviour. Recent evidence, however, suggests that people also form subjective norms when their referents themselves perform or do not perform the behaviour in question (Ajzen, 2006; Fishbein \& Ajzen, 2010). The former has been reconceptualised as injunctive norms, the latter as descriptive norms. In their respective aggregate, both injunctive norms and descriptive norms produce a subjective norm (or perceived social pressure) to perform (or not) a given behaviour (Fishbein \& Ajzen, 2010).

PBC refers to the extent to which the person perceives that performing (or not) the behaviour is under their volition control, a perception often containing two important components: controllability and self-efficacy (Armitage \& Conner, 2001). Controllability reflects external control factors such as the availability of resources and opportunities that enable a person to initiate the behaviour on their own volition, without imposed external restrictions. In contrast, self-efficacy refers to a person's own perceived self-confidence in their ability to perform a particular behaviour (Armitage \& Conner, 2001). Although comprised of these separable components, PBC has been found to be a unitary latent variable in a hierarchical factor model (Ajzen, 2006).

Generally speaking, the more favourable the attitude and subjective norm, and the greater the PBC, the stronger should be the person's intentions to perform the target behaviour (Ajzen, 1991). The stronger the level of intention and perceived behavioural control (PBC), the more likely the behaviour will be enacted. Empirical support for the predictive power of intentions over behaviour is widespread in the context of general education (e.g. Yan \& Sin, 2014, 2015), but less so in mathematics education (e.g. Pierce \& Ball, 2009). The theory has been previously used to investigate teachers instructional behaviour in Ghana (Kuyini \& Desai, 2007) and other contexts (Yan \& Sin, 2014), and could equally be useful in understanding the interplay between teacher's beliefs and their reform implementation decisions

\section{Study context}

Our primary purpose was to explore the determinants of teachers' intention to teach MPS in accordance with Ghanaian curriculum expectations of pupils engaging in moderate to vigorous MPS activities for least 60 percent of instructional time (MOE, 2014a). We assume attitudes (instrumental and affective), subjective norms (injunctive and descriptive norms) and PBC (selfefficacy and controllability) are positively related to a teacher's intention to engage their pupils in MPS activities. 
The behaviour component of the TPB model was excluded for two reasons. Firstly, teaching MPS was mandatory and not a matter of a teacher's personal choice. Secondly, and more importantly, we envisage that if teachers do not fully appreciate the advantages of teaching MPS, it can manifest itself as a 'resistance to change' (Hamilton-Roberts, 2012). However, the concept of resistance has often been criticised for carrying negative connotations and feelings (Hamilton-Roberts, 2012), given its predominant usage as part of an agenda that may overshadow teachers' legitimate reasons for objecting to change (Evans, 2001). Thus, instead of exploring why teachers are resisting change (or not teaching MPS), an assets-based perspective on resistance (i.e. studying "willingness") was pursued by examining factors that drive teachers to intend and implement change (Evans, 2001). By focusing on intentions, it was possible to understand potential underlying psychosocial factors in the change process, which could guide current mathematics reform agendas towards sustained change.

The research questions defining the study are:

RQ1. How well can the three measures of attitude, subjective norm and PBC predict teachers' intentions to teach mathematical problem solving, and which is the best predictor?

RQ2. How do primary teachers conceptualise mathematical problem solving, and what factors influence their intentions / willingness to teach such approaches?

\section{Methodological design}

An explanatory sequential mixed-methods research design was used to examine teachers' intentions to teach MPS in their classrooms, thus bringing about a more comprehensive understanding of the research problem (Creswell \& Plano Clark, 2011). A quantitative survey was initially conducted as the main source of data. The subsequent qualitative interviewing of a purposive sample of teachers enabled further interpretation of the quantitative results. By adopting this methodological approach, we partly aimed to demonstrate the relevance of using different methodological approaches in explaining teacher intentions. The study was conducted in line with the documented ethical framework of the second author's institution.

\section{Quantitative survey}

A quantitative cross-sectional survey of primary teachers in a large Ghanaian local authority was used to ascertain the significant determinants of teachers' intentions to teach MPS, in response to RQ1. A total of three hundred and seventy five ( $84 \%$ response rate) teachers from fifty public and private primary schools, selected via a two-stage stratified cluster sampling, completed and returned the questionnaires. Table 1 defines the sample. 
African Journal of Educational Studies in Mathematics and Sciences Vol..., 2019

Table 1: $\quad$ Profile of survey respondents $(n=375)$

\begin{tabular}{ll}
\hline Characteristic & Percentage of participants \\
\hline Gender & Male $(47 \%)$ \\
& Female $(52 \%)$ \\
& Unreported $(1 \%)$ \\
& $18-29$ years $(44 \%)$ \\
Age & $30-44$ years $(41 \%)$ \\
& $45+$ years $(13 \%)$ \\
& Unreported $(2 \%)$ \\
& Trained $(69 \%)$ \\
Level of Training & Untrained $(26 \%)$ \\
& Unreported $(5 \%)$ \\
& Beginning $[0-4$ years] (37\%) \\
Career Stage * & Advanced Beginners $[5-9$ years] $(26 \%)$ \\
& Expert $[10+$ years] $(37 \%)$ \\
\hline
\end{tabular}

* see Berliner (1994)

\section{Instrumentation}

An initial 'elicitation study' was used to support development of the 'teaching MPS' questionnaire (Authors, unpublished). The questionnaire comprised four scales to enable direct measures of the three TPB predictor variables and the intention construct. Direct measures are general questions (items) using standardised wording (Fishbein \& Ajzen, 2010; Francis et al., 2004) enabling respondent's perceptions of the target TPB constructs to be collected. Table 2 details the scales.

Table 2: Scales used in the questionnaire

\begin{tabular}{|c|c|c|c|}
\hline Scale & Type & Items & Example Statements \\
\hline \multirow[t]{2}{*}{ Attitude } & \multirow[t]{2}{*}{$\begin{array}{l}\text { 7-point semantic } \\
\text { differential }\end{array}$} & 3 (instrumental) & $\begin{array}{l}\text { 'Teaching MPS is good-bad, } \\
\text { worthless-useful' }\end{array}$ \\
\hline & & 2 (affective) & $\begin{array}{l}\text { 'Teaching MPS is pleasant-unpleasant, } \\
\text { interesting-boring' }\end{array}$ \\
\hline \multirow[t]{2}{*}{$\begin{array}{l}\text { Subjective } \\
\text { norm }\end{array}$} & \multirow[t]{2}{*}{ 7-point adjectival } & 2 (Injunctive) & $\begin{array}{l}\text { 'If I teach MPS, most people whose } \\
\text { opinion I value will approve'. }\end{array}$ \\
\hline & & 1 (Descriptive) & $\begin{array}{l}\text { 'Most people I respect and admire teach } \\
\text { MPS' }\end{array}$ \\
\hline \multirow{2}{*}{$\begin{array}{l}\text { Perceived } \\
\text { behavioural } \\
\text { control }\end{array}$} & \multirow[t]{2}{*}{$\begin{array}{l}\text { 7-point semantic } \\
\text { differential }\end{array}$} & 2 (Controllability) & $\begin{array}{l}\text { 'It is mostly up to me whether or } \\
\text { not to teach MPS.' }\end{array}$ \\
\hline & & 4 (Self-efficacy) & $\begin{array}{l}\text { 'How prepared do you feel you are to teach } \\
\text { MPS' }\end{array}$ \\
\hline Intention & 7-point adjectival & 5 (intentions) & 'I have planned to teach MPS' \\
\hline
\end{tabular}


The ordinal nature of Likert scales mean that although the response levels vary, it cannot be assumed that participants perceive the variation between adjacent levels to be equal (Pampaka, 2014). Some authors (e.g. Kislenko \& Grevholm, 2008) have highlighted the 'inappropriate' practice of conducting parametric statistics with such data. However, parametric statistics are generally robust with respect to ordinal scale data to the extent that they tend to give the 'right answer', even when measurement and statistical assumptions are violated (Norman, 2010).

The internal consistency of the teaching MPS questionnaire scales was examined using Cronbach's alpha reliability analysis (Tabachnick \& Fidell, 2013). The reliability index for attitude, subjective norm, $\mathrm{PBC}$ and intentions measures were $0.80,0.73,0.81$ and 0.93 , respectively, indicating high internal consistency (Ajzen, 2011). The instrument was pilot tested on a small subsection of the target population, resulting in modifications in item wordings and ordering.

\section{Data Analysis}

As in previous TPB studies (e.g. Hamilton-Roberts, 2012; Kang, 2007; Lee, Cerreto, \& Lee, 2010), multiple linear regression (MLR) analysis was used to explore how well the three predictor measures of the TPB (attitude, subjective norm and PBC) predict and explain the dependent variable (intentions to teach MPS) (RQ1). Before testing the predictive ability of the TPB model, to test for multicollinearity, the extent to which the predictor factors correlated was examined. A bivariate correlation analysis suggested that the factors correlated significantly, but moderately, amongst each other $(\mathrm{r}=0.27$ to $\mathrm{r}=0.41, \mathrm{p}<0.001)$, indicating both convergent and discriminant validity. To explore predictive ability, the coefficient of determination (R-squared) and standardized regression coefficients (beta) were used. The value of the coefficient of determination represents the proportion of variance in the outcome variable accounted for by the model. A conventional alpha level of 0.05 was used to evaluate statistical significance (Tabachnick \& Fidell, 2013).

\section{Qualitative Interviews}

The qualitative interviews initially explored teachers' conceptions about MPS, and subsequently attempted to understand more about the underlying reasons why they are willing (or not) to teach MPS (RQ2). We assumed that results from teachers own conceptions of teaching MPS could take account of potential conceptual issues such as teachers' beliefs of what teaching MPS looks like, or were due to teachers truly believing they are adopting appropriate practices for teaching MPS. On the other hand, knowledge of the underlying reasons why they are willing (or not) to teach MPS could provide indicators to teachers own past mathematics learning experiences, intentions to teach MPS (including what would motivate them to increase such intentions), and the associated opportunities and constraints.

\section{Instrumentation}

An interview guide was developed to support data collection. Specific questions related to the three TPB constructs were posed. This helped to uncover possible factors that could influence teacher intentions / willingness to teach MPS. Six teachers who took part in the initial quantitative survey volunteered to be part of the qualitative interviews. Table 3 defines the interviewee sample. 
African Journal of Educational Studies in Mathematics and Sciences Vol..., 2019

Table 3: $\quad$ Profiles of interview respondents $(n=6)$

\begin{tabular}{lllllll}
\hline Participant & A & B & C & D & E & F \\
\hline Grade Level & 4 & 5 & 4 & 6 & 2 & 1 \\
Gender & Female & Male & Female & Male & Female & Male \\
Age (years) & 26 & 51 & 19 & 48 & 30 & 31 \\
Level of Training & Trained & Untrained & Untrained & Trained & Trained & Trained \\
$\begin{array}{l}\text { Teaching Experience } \\
\text { (years) }\end{array}$ & 4 & 23 & 1 & 23 & 6 & 8 \\
\hline
\end{tabular}

A copy of their completed questionnaire was given to each interviewee to explain the basis of some of their responses, particularly where there appeared to be discrepancy between questionnaire and interview responses. This technique served as a form of triangulation used to achieve a higher degree of validity and reliability of the data collected (Creswell \& Plano Clark, 2011).

Data Analysis

Interview data analyses followed the conventions of template analysis, and an iterative coding process (King, 2012). Labelled grouping codes emerging from the textual data were categorized into the TPB constructs and developed into themes (Gibbs, 2007). For example, statements reflecting positive or negative beliefs about MPS were coded as attitudes, while statements about impediments to teaching MPS (e.g. limited MPS heuristic skills) were thematised and labelled as PBC. Across-transcript coding further uncovered explanations of the TPB constructs. Specific quotes were extracted to exemplify responses to RQ2.

Reflexive processes ensured that the analysis was not being systematically distorted by the researchers' own preconceptions and assumptions (King, 2012), for example, by returning to the participants to confirm whether the interpretations were correct. Qualitative findings were subsequently considered in the context of the survey data to provide deeper understanding of interconnections between beliefs, intentions and practice.

\section{Results}

Quantitative results: Descriptive statistics

Table 4 summarizes the distribution of means and standard deviations of the key variables. The mean intention score was 6.54 (standard deviation $(\mathrm{SD})=0.67$ ) indicating that the participants had strong intentions to teach MPS. The participants had high favourable attitudes toward MPS, and strong PBC over teaching MPS. For the subjective norm subscale, the participants' scores were at a moderate level (mean $=4.70, \mathrm{SD}=1.77)$, with the relatively higher $\mathrm{SD}$ value suggesting limited consensus of opinion. 
Exploring intentions to teach mathematical problem solving: An application of the Theory of Planned Behaviour

P. Hamidu-Armah and D. Robson

Table 4: Descriptive Statistics for predictor and outcome variables $(n=375)$

\begin{tabular}{lll}
\hline Construct & Mean & SD \\
\hline Intention to teach MPS & 6.54 & 0.67 \\
Attitude & 6.34 & 0.75 \\
Subjective Norm & 4.70 & 1.77 \\
PBC & 6.39 & 0.79 \\
\hline
\end{tabular}

Factors predicting primary teachers' intention to teach MPS to their pupils

Results indicate that the TPB is useful for predicting, as well as explaining variance in, primary teachers' intentions to teach MPS to their pupils. Findings are presented using the results from the MLR analysis (see Table 5).

Table 5: MLR Analysis: Parameter Estimates

\begin{tabular}{llll}
\hline Variable & Standardised beta $(\beta)$ & Zero-order & Probability value $(\mathrm{p})$ \\
\hline Constant & - & - & .00 \\
Attitude & $.29^{*}$ & .60 & .00 \\
Subjective norm & .01 & .30 & .66 \\
Perceived behavioural control (PBC) & $.74^{*}$ & .86 & .00 \\
R2 /adj R2 & $.804 / .802$ & & \\
\hline
\end{tabular}
$* \mathrm{p}<0.05$

The R-squared value confirmed that the three psychosocial factors (attitude, subjective norm and $\mathrm{PBC}$ ) collectively explained a significant variance (80\%) in teachers' intention to teach MPS. This indicates that the TPB model offers a useful avenue for understanding teacher classroom decisions (Yan \& Sin, 2015).

Path analysis (Figure 1) indicated that two factors, attitude (beta=0.29, $\mathrm{p}<0.05$ ), and PBC (beta $=0.74, \mathrm{p}<0.05$ ) were significant positive predictors of teachers' intentions to teach MPS, with $\mathrm{PBC}$ having the greatest effect. In contrast, subjective norm (beta $=0.013, \mathrm{p}>0.05$ ) had no statistically significant effect on intention, suggesting that the influence of perceived social pressure was overshadowed by the other factors. This result indicates that the influence of subjective norms on teacher intentions to teach MPS in this population of primary school teachers may not be as pervasive as the other two factors, but may still exist. The basis of this conclusion is that, as Fishbein and Ajzen (2010) argue, if the predictor has a high zero-order correlation with intention, it is likely to have at least some influence on the variable. In the present case, subjective norm has a moderate zero-order correlation with intention $(\mathrm{r}=0.30)$ and a very low regression coefficient (beta $=0.013$ ). Thus, it may be concluded that subjective norms may have some (but not statistically significant) influence on teacher intentions. 


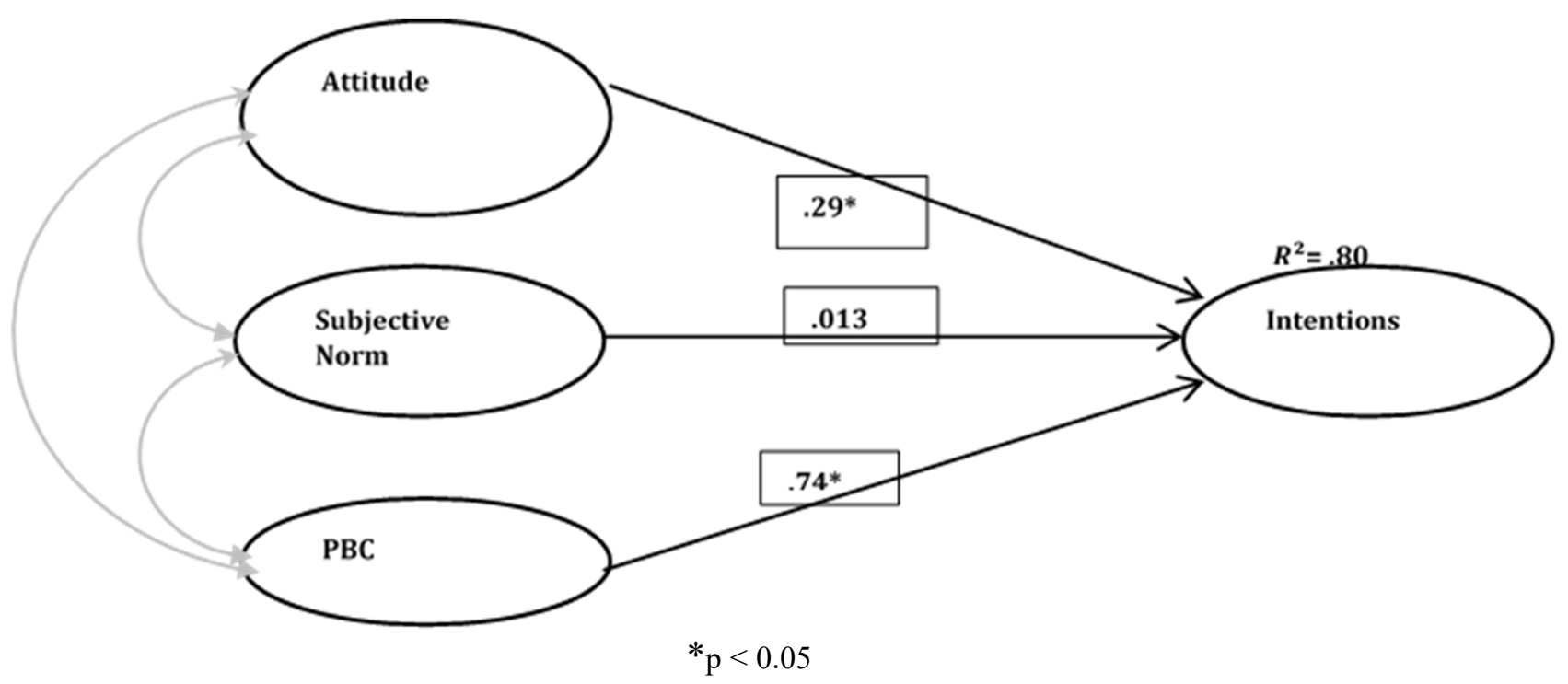

Figure. 1 Standardised solution for the TPB-based structural model of teachers' intentions to teach MPS.

\section{Qualitative Results: Teachers' conceptions of MPS and its teaching}

Template analysis revealed a general view that MPS relates to word or story problems, in which real life situations are modelled in statement forms for pupils to read, understand and solve. The mode of presentation of the problem situation was the determining factor - it must be stated in words. Selected comments from two teachers reflected this perspective:

Problem solving is just simple ...mathematical problems that have been written in sentence form. So it's about you reading and understanding and writing out the sentence to solve. That is how I see problem solving. They are in sentence, English sentence, so you have to read and bring out the maths in it and solve it to get your answer (Teacher C)

Let me use an example like profit and loss. The problem can be given in the sentence form, which the child has to read and then understand and bring out the cost price, the selling price as well as determine whether the question demand [finding] lost or profit (Teacher D).

MPS appears to be understood as any word problem that can be solved by applying computation or by transforming the problem into an equation for solution. This view means that pupils can answer the task by simply recalling and applying familiar solution patterns or problem schemata. This conception of MPS is limited. Some "story problems" are not problematic enough for pupils, and hence can be simply viewed as exercises for pupils to attempt.

\section{Qualitative Results: Factors influencing intentions/willingness to teach MPS}

Results pointed to three significant and interrelated sources of motivation for teaching MPS which could drive some teachers to develop stronger intentions, or be more willing, to teach MPS than others. 


\section{Perceived importance of MPs}

Teachers considered that MPS should have an important, prominent place in the mathematics education of pupils citing, most commonly, that teaching MPS has the potential to provide intellectual challenge that can enhance pupils' mathematical development. In addition, it was viewed that without problem solving pupils cannot study mathematics at higher levels, therefore restricting progression. Teaching MPS was considered to improve pupils reading skills, invoke cooperative skills, stimulate critical thinking, support the application of mathematics in everyday contexts and develop positive attitudes. As one teacher remarked:

It can help the child think faster, will have wider exploring opportunities, meaning, the child will not be narrow-minded, it will let the child explore (Teacher B)

Teachers believed that children who enjoy problem-solving activities are more likely to gain positive attitudes towards mathematics, because in the process of struggling with a problem, children can often obtain a deeper understanding of the underpinning mathematics. The novelty of the problem situation seems to add to pupils' interest.

\section{Perceived support from colleagues.}

Perceived support for teaching MPS was widespread. In response to the question "are there any persons who support your teaching MPS?, a typical response was "everyone". Most interviewees believed that their colleague teachers and head teachers would provide the administrative and instructional supports to enable MPS teaching. Conversely, they believed "no one" would disapprove of teaching MPS in their respective classrooms. Several accounts pointed to the invaluable contributions of colleagues at all levels. One participant stated:

... my friends help me; my colleagues also help me when I find something difficult, especially those who are good in math (Teacher E)

Another reported:

my head teacher, she is a person who encourages me a lot, so I wish one day to be like her to also motivate others (Teacher D).

Such supports from colleagues appeared to encourage primary teachers to continue to intend to teach MPS, and mainly manifested itself in the form of teachers' willingness to respond to requests for information, or those seeking the experiences of others. Other supports included head teachers preparedness to share their experience. Head teachers were considered the most influential group of people in terms of teachers' decisions on whether to teach MPS, since they often have responsibility for evaluating lesson content.

\section{Perceived Control over Teaching MPS}

The main factors identified as facilitating or obstructing teachers' intent/willingness to teach MPS appear to be funding, lack of equipment, inadequate instructional time, and classroom management challenges. These factors operated as both enablers and barriers to teacher's intentions, depending on their presence and absence respectively. As some teachers reflected: 
You see now the capitations1 are not coming, so if you need to do something you have to use your own money to go and buy cardboard. ... You need to show pupil to do something and if you don't have then you have to provide it yourself (Teacher D). - funding

I am saying the teaching and learning materials is not available, so it influences my planning. I don't have the syllabus and I don't have the teachers' guide, so how can I teach? (Teacher A). lack of equipment.

Some of them [pupils] try to explain it in their mother tongue to others, so that one also disrupts the class sometimes... one student getting up going this way, and the other getting up going that way (Teacher C). - classroom management difficulties

Teachers also perceived MPS as time consuming, especially in the context of constricted time allocation for mathematics, as they would have to first help the pupils develop conceptual understanding:

You see the work is more, and the time is limited. A child may take at least more of the time before coming [to understand] so it makes teaching a bit difficult. So I am entreating the curricular planners that ... we need more of the periods, (Teacher F).

\section{Discussion}

Consistent with previous studies (e.g. Lee, Cerreto and Lee, 2010; Yan \& Sin, 2014, 2015), the results indicated that the TPB offers a fruitful avenue to understand the underlying cognitive foundation for attitudinal, normative, and control beliefs that influence teachers' intentions. Teachers' willingness to teach MPS was determined by their attitudinal beliefs toward teaching MPS, their perceptions, and actions, of important others, and specific situational or perceived control difficulties. This finding supports the hypothesis that teachers, who hold positive attitudes, who feel social pressure, and who express confidence that they have control to teach MPS, equally hold strong intentions to teach MPS.

Compared with the other determinants, $\mathrm{PBC}$ was the strongest predictor of teachers' intentions followed by attitudinal beliefs. Although the influence of perceived social pressure on teachers' intentions did not reach statistical significance, its practical relevance was elucidated during the qualitative studies. Generally, there was strong evidence of the invaluable contributions of stakeholders on teachers' intentions to implement this aspect of the reform agenda (i.e. teaching MPS).

Results indicated that $80 \%$ of the variance in intentions can be explained by the three belief components of the TPB, therefore other factors, which remain to be identified, must also influence intentions to teach MPS. However, the $80 \%$ level is highly significant in comparison with earlier TPB studies. For example, Armitage and Conner (2001) found that the TPB model accounted for $27 \%$ and $39 \%$ of the variance in behaviour and intention, respectively. More recently, Lee, Cerreto and Lee (2010) used the TPB to examine the underlying beliefs and the relative strengths of the three direct determinants of teachers' intentions to utilize technology and found that they accounted for $70 \%$ of the variance. This led to their conclusion that the TPB performs well in comparison with other models of behaviour if precise definitions are used to determine the predictors of teachers' intentions, as was the case in the present study.

\footnotetext{
${ }^{1}$ Capitation is a special grant awarded to public schools in Ghana based on the number of recognised pupils' enrolment.
} 
The results also showed that PBC, and teachers' attitudes toward teaching MPS, had significant influence on the extent to which teachers were willing to try to teach MPS. Consistent with this finding, Teo, Koh \& Lee (2011) examined the efficacy of the TPB in explaining intention to teach financial literacy, concluding that, in that case, teachers were driven more by personal reasons than environmental factors. Attitudinal and control beliefs are factors that are pertaining to one's agency, in contrast to normative factors that involve other persons (Ajzen, 1991).

Aligning with TPB applications in the educational context (e.g. Faulkner, Reeves \& Chedzoy, 2004), the PBC measure displayed the strongest association with intention (beta=0.74). Although teachers' attitude (beta $=0.29$ ) was also a significant predictor of intentions, it was less influential than PBC. This finding differs from other TPB applications where attitude towards the behaviour is generally the strongest predictor of teachers' intentions (e.g. Lee, Cerreto, et al., 2010; Teo, Koh \& Lee 2011; Yan \& Sin, 2014, 2015). Crawley (1990), when examining science teachers' intentions to use investigative teaching methods, found that regardless of the availability of resources and time, intent to perform the behaviour appeared to be totally under the control of the participants, with little need for social support or validation from those making teaching decisions. The findings also disagreed with those of Haney, Czerniak et al. (1996) who found that the obstacles and enablers that teachers encountered mattered less to them than their beliefs regarding the outcomes, when using inquiry-based instruction. Yan and Sin (2015) attempted to explain and predict inclusive education intentions and practices of Principals in Hong Kong schools using the TPB. It emerged that their attitude and subjective norm were strong and significant predictors of their intention to implement inclusive education, whilst the predictive power of $\mathrm{PBC}$ on intention was not significant. In contrast, Faulkner, Reeves and Chedzoy (2004) found attitude to be less predictive of teachers' intentions than PBC.

In this study, the significance of $\mathrm{PBC}$ was uncovered by quantitative analysis (beta $=0.74, \mathrm{p}<0.05$ ), and subsequently through the qualitative analysis, where teachers identified the provision of resources as increasing their intentions. Funding, lack of equipment, inadequate instructional time, and classroom management challenges hindered their intentions to teach MPS. The provision of professional development in classroom behaviour management and access to resources may encourage teachers to want to teach MPS.

Findings from this study also suggest that teachers who intend to teach MPS are willing to exert effort to do so, since the hypothesised model suggests intentions depend on perceived self-efficacy and controllability (internal capacity) to teach MPS, and positive attitudes towards MPS. Therefore, to increase intentions, teachers need to be convinced of the importance and benefits of pupils' acquisition of problem solving skills (representing attitudes) and be empowered (e.g. through more funding, equipment, and improved classroom management skills) to teach it. Specifically, it may be argued that professional development (INSET) programmes must portray MPS as an area that teachers can learn and effortlessly teach their pupils to foster positive attitudes. At the same time, such programmes must provide support in the form of learning aids, teaching materials, and readily accessible and available guidance from experts.

\section{Conclusions}

This study has identified a number of beliefs which contribute significantly to attitude, subjective norms and PBC in teaching mathematical problem solving (MPS), thus providing an operational framework for improvement of these factors. The study has made significant contributions to 
understanding and research of the relevant social-cognitive processes which may influence teacher reform decisions in the domain specific area of MPS. It uncovered an important role for educational authorities in terms of supporting schools to develop teacher willingness, for example, through tailored professional development. Moreover, motivations underlying a teacher's decision to teach MPS (or not) have been highlighted, providing a basis for a behavioural change intervention for teachers and schools.

A framework for understanding the cognitive structure of teachers' willingness to teach MPS in particular, and undertake reform activities in general, has been suggested, although requiring further empirical testing of its adequacy for explaining this phenomenon. Furthermore, throughout the entire study, theoretical contributions have been made regarding any weaknesses and limitations of the TPB. The study also provided empirical support for the TPB as a useful schematic model to understand the behavioural intentions to implement reform teaching approaches (i.e. teaching MPS) among primary school teachers, whilst acknowledging its inherent limitations.

Finally, the study has provided empirical support for reforming teacher education programmes in Ghana to ensure incorporation of teachers' beliefs as a precursor to teacher change in this context. The study has also added theoretical knowledge to research on the role of social cognitive theories in defining curriculum implementation, offering potential leads for further work.

\section{Implications for Policy and Practice}

Based on the findings of this study and the body of research on effective teacher educational reform, several implications for teacher educators and policy makers are suggested.

The finding that teachers are willing (or have strong intentions) to teach MPS is determined, largely, by their PBC and attitudes, implies teachers' willingness could equally be weakened if they develop negative attitudes and/ or by adverse perceptions of control factors. Consequently, in order for teachers to want to teach MPS (or increase their intentions to do so), they should be convinced of the importance and benefits of MPS to their pupils, and be equipped with adequate resources.

Results specifically indicated that teachers were concerned that teaching MPS requires considerable amounts of instructional time. Hence, designers of teacher development programmes should emphasize methods to improve efficiency in mathematics lessons delivery. When pupils continually strive to identify patterns in MPS lessons, it eventually enables the teacher to cover ideas more quickly. Pupils who take time to develop their own ideas often demonstrate greater understandings, providing a solid grounding for future learning.

For this reason, offering support to teachers on how to manage their instructional time, may help them to appreciate more efficient use of their time, and increase their control beliefs over teaching MPS. In other words, time management must be an integral part of initial teacher education programmes. Alternatively, policy makers and curriculum developers could increase the time allocations for mathematics lessons to encourage teachers to modify their intentions favourably.

Although the finding that the perceived norm construct appeared to make limited contribution towards teachers' intentions to teach MPS is not surprising, it may be viewed as challenging. It appears that even if the teachers perceived that support structures were in place (e.g. approval from referent group), they did not value this support. This view is based on the pertinent notion that individuals develop normative beliefs by observing the actions and attitudes of other individuals 
Exploring intentions to teach mathematical problem solving: An application of the Theory of Planned Behaviour

P. Hamidu-Armah and D. Robson

(Ajzen, 2006). Therefore, policy interventions should help teachers understand that head teachers, education authorities, and colleagues are supportive of the teaching of MPS in classrooms, and that collaborative working with others has specific benefits for professional growth.

\section{Recommendations for Future Research}

Firstly, future research has the potential to explore changes to the key beliefs identified in this study by specifically testing the proposed model, and model expansion to include investigation of the relationship between intention and behaviour. A quasi-experimental, pre-test/ post-test design (Creswell \& Plano Clark, 2011) may be used for such an intervention with an experimental group and control group to enable exploration of the changing relationship. Given that personal considerations (attitudes and PBC) tend to overshadow the influences of social pressure regarding teachers' intentions to teach MPS, the interventions programme must aim at diffusing the importance of MPS to the experimental group, in addition to providing support to overcome identified barriers, whilst the control group receives no such assistance.

Secondly, future studies might examine the effects of additional training for teaching MPS, taking account of the findings of this study on primary school teachers' attitudes, PBC and intentions. Although most similar TPB studies focus on understanding the determinants of intentions /willingness, very few intervention studies exist where the findings are tested (Sosu, 2008).

Moreover, since teachers' attitudes and PBC regarding teaching MPS appear to be critical components in the curriculum implementation process, staff development opportunities must address the need to foster positive attitudes towards the reform agenda, as well as supporting teachers to build confidence in their own mathematical problem solving abilities and heuristics. Qualitative case studies with larger sample sizes which probe deeper into the belief structures of teachers may also be fruitful in understanding the teacher belief-intentions-behaviour relationship. Such qualitative case studies should track teachers through the belief change process, and report factors associated with changes in their belief structures and subsequent classroom practices.

\section{Study Acknowledgements}

This research received financial support from the Ghana Education Trust Fund (GETFund), a public sector educational financing agency for the promotion of research, especially at the tertiary level in Ghana. For this support we are most grateful.

\section{References}

Ajzen, I., (1991). The theory of planned behaviour. Organizational behaviour and human decision processes, 50(2), 179-211.

Ajzen, I., (2006). Constructing a TPB Questionnaire: Conceptual and Methodological Considerations. http://people.umass.edu/aizen/pdf/tpb.measurement.pdf [Accessed: 24 May 2018]

Ajzen, I., (2011). The theory of planned behaviour: Reactions and reflections. Psychology \& Health, 26 (9), 1113-1127.

Ampadu, E. (2012). Investigation into the teaching and learning of mathematics in junior secondary schools: the case of Ghana. Thesis (PhD). Anglia Ruskin University. 
African Journal of Educational Studies in Mathematics and Sciences Vol..., 2019

Anamuah-Mensah, J., Mereku, D.K., and Ameyaw-Asabere, A. (2004). Ghanaian junior secondary school students' achievement in mathematics and science: Results from Ghana's participation in the 2003 Trends in International Mathematics and Science Study. Accra: Ministry of Education Youth and Sports, 2004.

Anderson, J. (2009). Mathematics curriculum development and the role of problem solving. In Proceedings of 2009 Australian Curriculum Studies Association National Biennial Conference. Curriculum: A National Conversation, (pp. 1-8).

Armah, P. H. (2017). Influences on students' Math and Science learning outcomes: Evidence from Ghana's SEIP schools. MoE, Accra.

Armitage C. J. and Conner M. (2001). Efficacy of the theory of planned behaviour: A metaanalytic review. British Journal of Social Psychology. 40, 471- 499.

Berliner, D. C. (1994). Expertise: The wonders of exemplary performance. In J. N. Mangieri \& C. C. Block (Eds.), Creating powerful thinking in teachers and students (pp. 141-186). Forth Worth, TX: Harcourt Brace.

Crawley, F. E. (1990). Intentions of science teachers to use investigative teaching methods: A test of the theory of planned behavior. Journal of Research in Science Teaching, 27, 685-697.

Creswell, J. W., \& Plano Clark, V. (2011). Designing and Conducting Mixed Methods Research. Sage. Thousand Oaks, CA.

Ernest, P. (2004). The philosophy of mathematics education. Taylor and Francis e-Library (Adobe e Reader Format). http://p4mriunpat.files.wordpress.com/2011/10/the-philosophy-ofmathematics-education-studies-in-mathematicseducation.pdf [Accessed: 24 May 2018].

Evans, R. (2001). The human side of school change: Reform, resistance, and the real-life problems of innovation. San Francisco, CA: Jossey-Bass

Faulkner, G., Reeves, C., \& Chedzoy, S. (2004). Nonspecialist, preservice primary-school teachers: Predicting intentions to teach physical education. Journal of Teaching in Physical Education, 23(3), 200-215.

Fishbein, M., \& Ajzen, I. (2010). Predicting and Changing Behaviour: The reasoned action approach. New York, NY: Psychology Press, Taylor \& Francis Group. .

Francis, J. J., Eccles, M. P., Johnston, M., Walker, A., Grimshaw, J. M., Foy, R., and Bonetti, D. (2004). Constructing questionnaires based on the theory of planned behaviour-A manual for health services researchers. Newcastle: Centre for Health Service Research, University of Newcastle

Gibbs, G. R., (2007). Thematic coding and categorizing. Analyzing Qualitative Data. London: SAGE Publications, Ltd

Hamilton-Roberts, A. (2012). A proposed model for predicting the willingness of mainstream secondary teachers to support the mental health needs of pupils. Thesis (Psy.D). Cardiff University.

Haney, J. J., Czerniak, C. M., \& Lumpe, A. T. (1996). Teacher beliefs and intentions regarding the implementation of science education reform strands. Journal of Research in Science Teaching, 33(9), 971-993. 
Exploring intentions to teach mathematical problem solving: An application of the Theory of

Planned Behaviour

P. Hamidu-Armah and D. Robson

Her Majesty's Inspectorate,(HMI) (1985). Education 8-12 in combined and middle schools. Her Majesty's Stationery Office, London

Herrera, T. A., and Owens, D. T. (2001). The "new new math" ?: Two reform movements in mathematics education. Theory into Practice, 40(2), 84-92.

Kang, R. (2007). PK-8 preservice teachers intentions to teach economics: an application of the theory of reasoned action and the theory of planned behaviour (Doctoral dissertation, Texas A\&M University).

King, N. (2012). Doing template analysis. Qualitative organizational research: Core methods and current challenges, (pp.426-450). London: SAGE Publications.

Kislenko, K., \& Grevholm, B. (2008). The Likert scale used in research on affect - a short discussion of terminology and appropriate analyzing methods. Paper presented at the 11th International Congress on Mathematical Education, Monterrey, Mexico.

Kuyini, A. B., \& Desai, I. (2007). Principals' and teachers' attitudes and knowledge of inclusive education as predictors of effective teaching practices in Ghana. Journal of Research in Special Educational Needs, 7(2), 104-113.

Lee, J., Cerreto, F. A., \& Lee, J. (2010). Theory of planned behaviour and teachers' decisions regarding use of educational technology. Journal of Educational Technology \& Society, 13(1), 152-164.

Ministry Of Education (MOE) (2014a). Report on Basic Statistics and Planning Parameters for Basic Education in Ghana 2013/2014. Accra-Ghana: EMIS

Ministry Of Education (MOE) (2014b). Ghana 2013 Early Grade Reading Assessment and Early Grade Mathematics Assessment Report of Findings. Accra-Ghana: EMIS.

Ministry Of Education (MOE). (2012). Teaching syllabus for Mathematics (Primary School 1-6). Accra-Ghana: Curriculum Research and Development Division (CRDD).

Ministry Of Education, Science and Sports (MOESS)., (2007). Teaching syllabus for Mathematics (Junior High School 1-3). Accra-Ghana: Curriculum Research and Development Division (CRDD).

Ministry Of Education, Science And Sports (MOESS)., (2008). Preliminary Education Sector Performance report 2008. Accra-Ghana: MOESS.

Mullis, I. V. S., Martin, M. O., Foy, P., And Arora, A., (2012). TIMSS 2011 International Mathematics Report: Findings from IEA's Trends in International Mathematics and Science Study at the Fourth and Eighth Grades. Chestnut Hill, MA: Boston College.

National Council of Teachers of Mathematics (NTCM). (1980). An Agenda for Action: Recommendations for school mathematics of the 1980s. Reston, VA: Author.

National Research Council [NRC]. (2001). Adding it up: Helping children learn mathematics. In J. Kilpatrick, J. Swafford, and B. Findell (Eds.). Mathematics Learning Study Committee, Centre for education, Washington, DC: National Academy Press.

Norman, G. (2010). Likert scales, levels of measurement and the "laws" of statistics. Advances in health sciences education, 15(5), 625-632. 
Norton, L., Richardson, T., Hartley, J., Newstead, S., \& Mayes, J. (2005). Teachers' beliefs and intentions concerning teaching in higher education. Higher Education, 50(4), pp. 537-571.

OECD (2013), PISA 2012 Assessment and Analytical Framework: Mathematics, Reading, Science, Problem Solving and Financial Literacy. OECD Publishing. http://dx.doi.org/10.1787/9789264190511-en [Date Accessed: 24 May 2018]

OECD (2009). Teaching practices, teachers beliefs and attitudes. http://www.oecd.org/berlin/43541655.pdf [Date Accessed: 24 May 2018]

Pierce, R., \& Ball, L. (2009). Perceptions that may affect teachers' intention to use technology in secondary mathematics classes. Educational Studies in Mathematics, 71(3), 299-317.

Polly, D., Mcgee, J. R., Wang, C., Lambert, R. G., Pugalee, D. K., \& Johnson, S. (2013). The Association between Teachers' Beliefs, Enacted Practices, and Student Learning in Mathematics. Mathematics Educator, 22(2), 11-30.

Pampaka, M., (2014). Mathematical Problem Solving: Teachers'Attitudes, Knowledge, Beliefs and Practices. Germany: LAP LAMBERT Academic Publishing.

Sosu, E., (2008). Unearthing the Complexities in Environmental Education Teaching Behaviour: A Pragmatic and Systemic Approach. Thesis (PhD), University of Strathclyde.

Tabachnick, B. Fidell (2013). Using multivariate statistics. 6th Edn. Boston: Pearson Education

Teo, T., Koh, N. K., \& Lee, C. B. (2011). Teachers' intention to teach financial literacy in Singapore: A path analysis of an extended Theory of Planned Behaviour (TPB). The AsiaPacific Education Researcher, 20(2), 412-421.

Wilson, C., Woolfson, L. M., Durkin, K., \& Elliott, M. A. (2016). The impact of social cognitive and personality factors on teachers' reported inclusive behaviour. British Journal of Educational Psychology, 86(3), 461-480.

Yan, Z., \& Sin, K. F. (2014). Inclusive education: teachers' intentions and behaviour analysed from the viewpoint of the theory of planned behaviour. International Journal of Inclusive Education, 18(1), 72-85.

Yan, Z., \& Sin, K. F. (2015). Exploring the intentions and practices of principals regarding inclusive education: an application of the Theory of Planned Behaviour. Cambridge Journal of Education, 45(2), 205-221. 